\title{
Incremento del conocimiento en soporte vital básico facilitado por un recurso educativo digital
}

\section{Basic life support knowledge acquisition using a digital educational resource}

\section{Incremento do conhecimento em suporte vital básico facilitado por um recurso educativo digital}

\author{
D. Blanco-Ávila ${ }^{\mathrm{a}^{*}}$, J. Gómez-Leal ${ }^{\mathrm{b}}, \mathrm{X}$. Sáenz-Montoya ${ }^{\mathrm{c}}$ \\ ORCID: \\ ${ }^{a}$ https://orcid.org/oooo-0001-5146-2721 \\ ${ }^{b}$ https://orcid.org/0000-0002-4002-8716 \\ c https://orcid.org/o000-0002-0775-6690
}

Universidad Nacional de Colombia, Facultad de Enfermería, Departamento de Enfermería Sede Bogotá, Bogotá, Colombia

Recibido: 6 septiembre 2019 / Aceptado: 21 enero 2020

RESUMEN

Introducción: La enfermedad cardiovascular es responsable de 17.3 millones de muertes por año en el mundo y conlleva a complicaciones como el paro cardiorrespiratorio, el cual se puede presentar tanto en el escenario intra como extrahospitalario. Tener una comunidad capacitada posibilita la sobrevida y/o mitigación de secuelas. Con el propósito de aumentar la población capacitada en soporte vital básico, favorecer el aprendizaje y dedicar más tiempo al desarrollo de habilidades prácticas, se construyó un recurso educativo digital.

Objetivo: Determinar el efecto de un recurso educativo digital en el proceso de aprendizaje de soporte vital básico en integrantes de la comunidad de una institución de educación superior.

Métodos: Estudio cuantitativo, pre-experimental tipo pre-prueba/pos-prueba en un solo grupo.

Resultados: El recurso educativo digital para el aprendizaje de soporte vital básico en 110 estudiantes incrementó el conocimiento, mostró una diferencia estadísticamente significativa en los resultados del post-test en comparación con el pre-test: $\mathrm{p}<0.01$ para grupos ajustados al modelo gaussiano y p<0.05 para el grupo no ajustado. 
Discusión: Los resultados de implementar un recurso educativo digital para la enseñanza de soporte vital básico es consecuente con los beneficios hallados en otros estudios similares. Los Objetos Virtuales de Aprendizaje favorecen en los estudiantes la motivación, el aprendizaje autorregulado y la apropiación de conocimientos, por lo que los proponen como estrategia de aprendizaje.

Conclusión: El recurso educativo digital favoreció el aprendizaje e incrementó el conocimiento, requisito necesario en la formación como primer respondiente en los tres grupos de estudiantes de pregrado que participaron en el presente estudio.

Palabras clave: Reanimación cardiopulmonar; paro cardíaco; evaluación educacional; educación a distancia; Colombia.

\section{ABSTRACT}

Introduction: Cardiovascular diseases are accountable for 17.3 million deaths per year in the world. Cardiac arrests can happen anywhere. Therefore, having a correspondingly trained community can increase the survival chance and decrease the possible aftermath of those suffering complications.

Objective: To estimate the effect of using a digital educational resource in the learning process related to basic life support among participants of a higher education institution.

Methods: This is a quantitative, pre-experimental, pre-test-post-test study on a single group Results: The use of a digital educational resource in the learning process related to basic life support increased knowledge acquisition in 110 students, demonstrating a statistically significant difference between the pre-test and post-test levels ( $p<0.01$ for the gaussian model adjusted group, and $\mathrm{p}<0.05$ for the unadjusted one).

Discussion: These results are consistent with the findings of other similar studies. Since Virtual Learning Objects can foster motivation, self-regulated learning, and knowledge acquisition among students, this methodology is recommended as a complementary learning strategy.

Conclusion: The digital educational resource increased knowledge acquisition related to basic life support among the participating students, making them better suited to address possible complications of cardiovascular diseases.

Keywords: Cardiopulmonary resuscitation; cardiac arrest; education assessment; distance education; Colombia.

\section{RESUMO}

Introdução: A doença cardiovascular é responsável de 17.3 milhões de mortes por ano no mundo e envolve a complicações como a paragem cardiorrespiratória, o qual se pode apresentar tanto no cenário intra como extra-hospitalar. Ter uma comunidade capacitada possibilita a sobrevida e/ou mitigação de sequelas. Com o propósito de aumentar a população capacitada em suporte vital básico, favorecer a aprendizagem e dedicar mais tempo no desenvolvimento de habilidades práticas, construiu-se um recurso educativo digital.

Objetivo: Determinar o efeito de um recurso educativo digital no processo de aprendizagem de suporte vital básico em integrantes da comunidade de uma instituição de educação superior.

Métodos: Estudo quantitativo, pre-experimental tipo pre-teste/pos-teste apenas em um grupo. 
Resultados: O recurso educativo digital para a aprendizagem de suporte vital básico em 110 estudantes incrementou o conhecimento, mostrou uma diferença estatisticamente significativa nos resultados do post-teste em comparação com o pre-teste: $\mathrm{p}<0.01$ para grupos ajustados ao modelo gaussiano e p<0.05 para o grupo não ajustado.

Discussão: Os resultados para desenvolver um recurso educativo digital para o ensino de suporte vital básico, é consequente com os benefícios encontrados em outros estudos similares. Os Objetos Virtuais de Aprendizagem favorecem aos estudantes na motivação, na aprendizagem autorregulada e na apropriação de conhecimentos, pelo que os propõem como estratégia de aprendizagem.

Conclusão: O recurso educativo digital favoreceu na aprendizagem e incrementou o conhecimento, requerimento necessário na formação como primeiro respondente nos três grupos de estudantes de pré-grau que participar no presente estudo.

Palavras chave: Reanimação cardiopulmonar; paragem cardíaca; avaliação educacional; educação a distancia; Colômbia.

\section{INTRODUCCIÓN}

La enfermedad cardiovascular es la responsable de la muerte de 17.3 millones de personas por año en el mundo y se espera que para 2030 ese número ascienda a 23.6 millones de fallecimientos por esta causa ${ }^{1}$. Según la Asociación Europea de Cardiología, la enfermedad coronaria es la causa más frecuente de muerte en todo el mundo, responsable de casi 1.8 millones de muertes al año².

En Colombia, la enfermedad isquémica cardiaca es la principal causa de muerte en personas mayores de 55 años 3 . Las patologías cardiovasculares conllevan a complicaciones letales, entre ellas, el paro cardiorrespiratorio (PCR), el cual se presenta tanto en el escenario intrahospitalario como en el extrahospitalario. Estudios aseguran que el PCR debe considerarse un problema de salud pública. En los países desarrollados, de cada 1000 pacientes hospitalizados, 6 presentan PCR; entre tanto, a nivel extrahospitalario se afirma que la incidencia es de 50-55/100,00o habitantes/año4.

Un estudio realizado en Estados Unidos analizó 1165 casos de PCR y concluyó que este evento se presenta con mayor frecuencia en hombres, con una mediana de edad de 64 años. El $30 \%$ de los casos fue presenciado por alguna persona que no tenía conocimiento en reanimación, y se le dificultaba seguir las indicaciones telefónicas del operador de emergencias debido a la conmoción emocional; así mismo, el estudio evidenció la fibrilación ventricular y la taquicardia ventricular sin pulso como los principales ritmos de paro. Finalmente, asegura que la probabilidad de sobrevida de estos pacientes disminuye entre un $7 \%$ a un $10 \%$ por cada minuto que se tarde la desfibrilación ${ }^{5}$. Entre tanto, cuando la desfibrilación se administra durante los primeros siete minutos, el índice de supervivencia oscila entre el $30 \%$ y el $45 \%^{6}$.

El PCR debe prevenirse en el contexto hospitalario; sin embargo, su manejo en el ámbito extrahospitalario constituye un verdadero desafío cotidiano, en el que sólo el $28 \%$ de las personas retornan a la circulación espontánea?. Por otra parte, las variables que pueden conducir al éxito reflejan en gran medida la calidad estructural del Sistema de Emergencias Médicas (SEM) ${ }^{8}$. Un estudio realizado en Uruguay concluyó que el 82\% de eventos de PCR extrahospitalarios se presentaron en el hogar o trabajo y el 18\% en vía pública, siendo los familiares o transeúntes, los responsables de asumir la atención de la víctima9.

Organizaciones como la European Resuscitation Council (ERC), y la American Heart Association (AHA) han desarrollado guías dirigidas a profesionales de la salud y personas de la comunidad que 
puedan atender inicialmente los eventos, a los que se denomina primer respondiente. La capacitación en Soporte Vital Básico (SVB) pretende que las personas ejecuten acciones secuenciales, con el objetivo de restablecer rápidamente la circulación espontánea y disminuir las complicaciones en estos pacientes ${ }^{10}$.

Tener una comunidad capacitada contribuye a una atención oportuna y adecuada que repercute en la posibilidad de sobrevida y/o mitigación de secuelas. En ese sentido la AHA asegura que los pacientes que sufren un PCR extrahospitalario dependen de la asistencia que se les preste en su comunidad; sugiere que la morbimortalidad podría reducirse en forma significativa si el $20 \%$ de la población iniciara SVB ${ }^{11}$. Para esto, la comunidad debe reconocer el paro cardíaco, pedir ayuda, iniciar reanimación cardiopulmonar (RCP) de calidad y realizar la desfibrilación hasta que llegue el equipo médico; sin embargo, esto sucede sólo en menos del $25 \%$ de los casos ${ }^{6}$.

Como una estrategia que responda a la necesidad de contar con una comunidad capacitada en SVB, un grupo de profesores de la Facultad de Enfermería de la Universidad Nacional de Colombia creó el proyecto de extensión Solidaria UN SALVAVIDAS. Este proyecto tiene como objetivo capacitar a la comunidad universitaria para actuar como primer respondiente. Al hablar de comunidad universitaria se hace referencia a estudiantes, docentes y administrativos. El presente estudio incluyó exclusivamente a tres grupos de estudiantes del área de la salud, quienes solicitaron participar en el proyecto durante este período académico y a su vez fueron los primeros en cursar el recurso educativo digital en su última versión.

El proyecto vincula estudiantes del programa de Enfermería, que son formados como instructores de soporte vital básico y, posteriormente, capacitar a la comunidad universitaria por medio de un curso teórico-práctico. En los inicios del proyecto, el componente teórico se desarrollaba de forma presencial en el aula de clase y el componente práctico en escenarios simulados en el Laboratorio de Simulación de la Facultad de Enfermería con el propósito de aumentar la población capacitada, dinamizar y favorecer el aprendizaje del participante en referencia al componente teórico. Además, al dedicar más tiempo al desarrollo de habilidades prácticas, se implementa como estrategia pedagógica, la educación digital. Para lograr estos objetivos, en 2017 se crea un recurso educativo digital de aprendizaje, denominado Soporte Vital Básico, el cual está disponible en la plataforma Moodle.

Respecto a la educación digital, la AHA refiere que las habilidades de SVB se adquieren con la misma facilidad mediante autoaprendizaje (videos y/o uso de computadores) combinado con práctica ${ }^{6}$. Por otra parte, los objetos digitales son una estrategia de aprendizaje que posibilita la articulación con ambientes de aprendizaje en otros espacios y con otros actores educativos ${ }^{12}$.

El objetivo del presente estudio es determinar el efecto de un recurso educativo digital en el aprendizaje de soporte vital básico en integrantes de la comunidad de una institución de educación superior.

\section{MATERIALES Y MÉTODOS}

Estudio cuantitativo, pre-experimental tipo pre-prueba/pos-prueba con un solo grupo ${ }^{13}$. La prueba inicial corresponde al pre-test de conocimientos en SVB; el estímulo hace referencia al recurso educativo digital y la evaluación final al post-test.

La muestra correspondió a 110 estudiantes de los programas de Farmacia, Odontología y Enfermería. Se consideraron como criterios de inclusión pertenecer a la comunidad de la Universidad Nacional de Colombia - Sede Bogotá; haber cursado el 100\% del recurso educativo digital para el aprendizaje de SVB durante el periodo académico en el que se llevó a cabo el estudio. Se excluyeron 
aquellos participantes que no terminaron la totalidad del recurso educativo o no presentaron alguna de las dos pruebas. La información se obtuvo de los resultados de las dos pruebas.

\section{Intervención o estímulo}

El estímulo lo constituyó un recurso educativo digital para el aprendizaje de SVB, el cual se desarrolla a través de la plataforma Moodle y tiene como propósito facilitar el aprendizaje del SVB para contribuir a la formación como primer respondiente. Fue diseñado de tal forma que el participante pueda navegar por los contenidos de manera libre; inicia con la prueba pre-test que consta de 15 preguntas cuyo objetivo es indagar sobre los conocimientos previos de los participantes para realizar acciones de primer respondiente. Una vez finalizado el pre-test, el participante estudia los 7 módulos que contienen las temáticas de SVB del adulto y pediátrico, obstrucción de la vía aérea por cuerpo extraño (OVACE), síndrome coronario agudo (SCA) y accidente cerebrovascular (ACV).

Los módulos contienen videos, animaciones, y explicaciones que ilustran al participante el proceso para identificar la situación, activar el sistema de emergencias médicas e iniciar las acciones de primer respondiente. Cada participante es matriculado en el recurso 8 días antes de la sesión práctica, de tal forma que pueda navegar libremente por los contenidos del recurso.

Al finalizar, el participante realiza la prueba post-test para evaluar los conocimientos que adquirió durante el desarrollo de cada uno de los módulos. Este post-test contiene las mismas preguntas del pre-test. En el noveno día, el participante asiste a la sesión práctica de 6 horas basada en simulación para completar el ciclo de aprendizaje de SVB, dirigida, evaluada y certificada por los instructores.

La simulación como innovación educativa en la RCP otorga un ambiente seguro para el entrenamiento de personas, impactando positivamente en la atención del paciente y permitiendo el desarrollo de destrezas ${ }^{14}$.

Para el análisis de los datos se emplearon estadísticos descriptivos, se analizaron medidas estadísticas de tendencia central como media y mediana, y de dispersión como desviación estándar, varianza, mínima y máxima ${ }^{15}$. Para comparar las mediciones pre y post prueba se utilizó el test de Wilcoxon con rango signado ${ }^{16}$, dado que mediante el de Kolgomorov Smirnov se evidenció que las variables de interés no se ajustaron al modelo gaussiano, para los grupos de enfermería y odontología. En el caso del grupo de Farmacia, se usó el estadístico T de Student dado que hubo ajuste al modelo gaussiano. Para realizar este análisis, se utilizó el software SPSS versión 24.

En referencia a los aspectos éticos, el proyecto de Extensión solidaria UN SALVAVIDAS está aprobado por la Facultad de Enfermería según oficio SA 252 de 2015, y el presente estudio recibió recibió consentimiento ético mediante AVAL-031-18 del o7 de junio de 2018. Asimismo, adoptó los lineamientos de Resolución 8430 de 1993 y se considera como una investigación de bajo riesgo, dado que emplea el registro de datos a través de procedimientos comunes ${ }^{17}$; la unidad de análisis fueron los resultados de pre-test y pos-test y se mantuvo la confidencialidad de los participantes. Además, preserva los lineamientos del respeto de la propiedad intelectual establecidos en el acuerdo O352003 del Consejo Superior Universitario de la Universidad Nacional de Colombia y el Tratado de la Organización Mundial de la Propiedad Intelectual sobre derechos de autor ${ }^{18}$.

\section{RESULTADOS}

110 participantes fueron incluidos en el estudio: 24 estudiantes del programa de Farmacia, 49 estudiantes del programa de Odontología y 37 estudiantes del programa de Enfermería; en este semestre no participaron administrativos o profesores. 
Al realizar el análisis estadístico de los resultados del pre test y el post test de los tres grupos, se encontró que sólo el grupo de farmacia se ajustó al modelo gaussiano, por lo cual se optó por una prueba de comparación $\mathrm{T}$ de Student para muestras relacionadas, con intervalo de confianza del 95\%. Se encontró una diferencia estadísticamente significativa ( $p<0.05$ ) (Tabla 1), la cual, al remontarse a los estadísticos descriptivos, permite observar un considerable aumento de la media en el post-test; se demuestra que el recurso educativo digital tiene un efecto positivo en los participantes al incrementar el conocimiento en SVB (Tabla 2).

Para comparar los resultados del pre-test y post-test de los grupos de Odontología y Enfermería sometidos al estímulo (recurso educativo digital), se realizó la prueba de Kolgomorov Smirnov, la cual evidenció que las variables de interés no se ajustaron al modelo gaussiano, por lo que se optó por una prueba de Wilcoxon con rango signado para muestras relacionadas. Esto permitió hacer la comparación y brindó como resultado una diferencia estadísticamente significativa entre el pre y post test del estudio $\mathrm{p}<0.01$, lo cual se apoya en los descriptivos de los dos grupos (Ver tabla 2); se observó que los resultados de la mediana aumentaron significativamente en la post prueba, lo cual demuestra nuevamente que el recurso educativo digital tiene un efecto positivo en los participantes, al incrementar el conocimiento en SVB.

Tabla 1. Prueba T de Student, grupo de Farmacia

\begin{tabular}{|c|c|c|c|c|c|c|c|c|}
\hline \multicolumn{9}{|c|}{ Prueba de muestras emparejadas } \\
\hline & \multicolumn{5}{|c|}{ Diferencias emparejadas } & \multirow[b]{3}{*}{$t$} & \multirow[b]{3}{*}{$\mathrm{Gl}$} & \multirow[b]{3}{*}{$\mathrm{p}$} \\
\hline & \multirow[b]{2}{*}{ Media } & \multirow{2}{*}{$\begin{array}{l}\text { Desviación } \\
\text { estándar }\end{array}$} & \multirow{2}{*}{$\begin{array}{c}\text { Media de error } \\
\text { estándar }\end{array}$} & \multicolumn{2}{|c|}{$\begin{array}{c}\text { 95\% de intervalo de } \\
\text { confianza de la diferencia }\end{array}$} & & & \\
\hline & & & & Inferior & Superior & & & \\
\hline Prueba Pre-Test & & & & & & & & \\
\hline Prueba Post-Test & -1.86 & 0.79 & 0.16 & -2.20 & -1.53 & -11.54 & 23 & 0.000 \\
\hline
\end{tabular}

Tabla 2: Estadísticos descriptivos, grupo de Farmacia, Odontología y Enfermería.

\begin{tabular}{|c|c|c|c|c|c|}
\hline Grupo & $\begin{array}{c}\text { Número de } \\
\text { Casos Válidos }\end{array}$ & $\begin{array}{c}\text { Número de Casos } \\
\text { perdidos }\end{array}$ & Variable & $\begin{array}{l}\text { Prueba } \\
\text { Pre-Test }\end{array}$ & $\begin{array}{c}\text { Prueba } \\
\text { Post-Test }\end{array}$ \\
\hline \multirow{5}{*}{$\begin{array}{l}\text { Estudiantes de } \\
\text { Farmacia }\end{array}$} & \multirow[t]{5}{*}{24} & \multirow[t]{5}{*}{0} & Media & 2.70 & 4.56 \\
\hline & & & Mediana & 2.85 & 4.62 \\
\hline & & & Desviación estándar & 0.78 & 0.33 \\
\hline & & & Nota Mínima & 1.20 & 3.80 \\
\hline & & & Nota Máximo & 5.00 & 5.00 \\
\hline \multirow{5}{*}{$\begin{array}{l}\text { Estudiantes } \\
\text { Odontología }\end{array}$} & \multirow[t]{5}{*}{49} & \multirow[t]{5}{*}{ o } & Media & 2.49 & 4.42 \\
\hline & & & Mediana & 2.53 & 4.53 \\
\hline & & & Desviación estándar & 0.83 & 0.39 \\
\hline & & & Mínimo & 0.73 & 3.33 \\
\hline & & & Máximo & 4.53 & 5.00 \\
\hline \multirow{5}{*}{$\begin{array}{l}\text { Estudiantes } \\
\text { Enfermería }\end{array}$} & \multirow[t]{5}{*}{37} & \multirow[t]{5}{*}{ o } & Media & 3.38 & 4.61 \\
\hline & & & Mediana & 3.46 & 4.66 \\
\hline & & & Desviación estándar & 0.73 & 0.36 \\
\hline & & & Mínimo & 1.32 & 3.86 \\
\hline & & & Máximo & 4.86 & 5.00 \\
\hline
\end{tabular}


Al ilustrar las variables en el diagrama de Caja-Bigotes, se hace evidente el aumento del nivel en el post-test frente al pre-test en los tres grupos; adicional a esto, muestra cómo logran compactarse, se alcanzan en su mayoría notas superiores y disminuyen la dispersión de los resultados (Gráfica 1, 2 y 3).

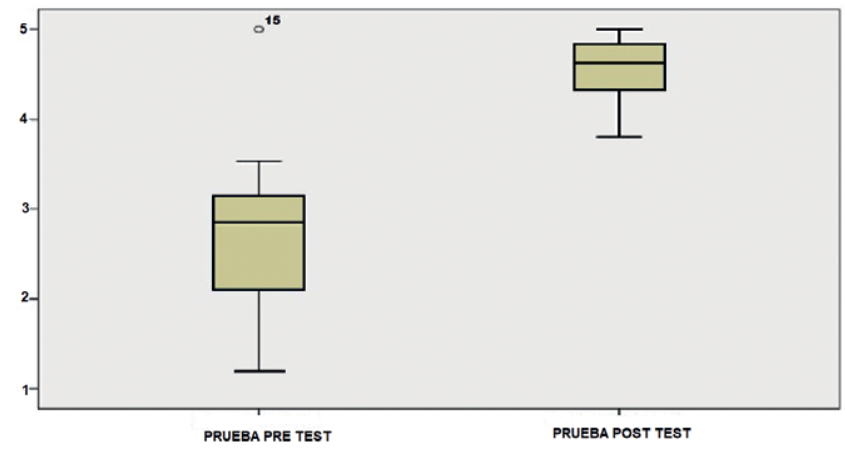

Gráfica 1. Comparación prueba pre-test y post-test, grupo de farmacia.

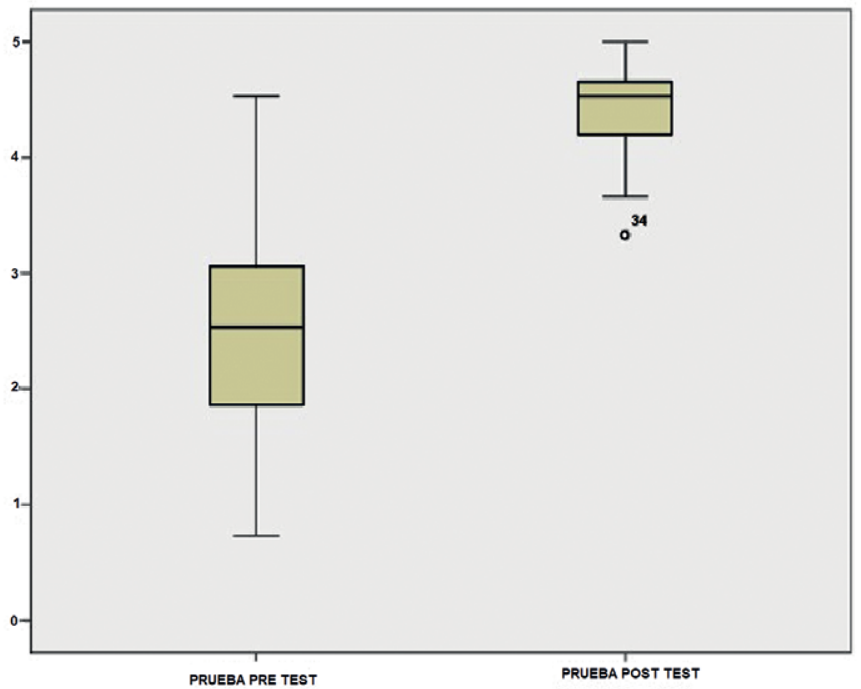

Gráfica 2. Comparación prueba pre-test y post-test, grupo de Odontología.

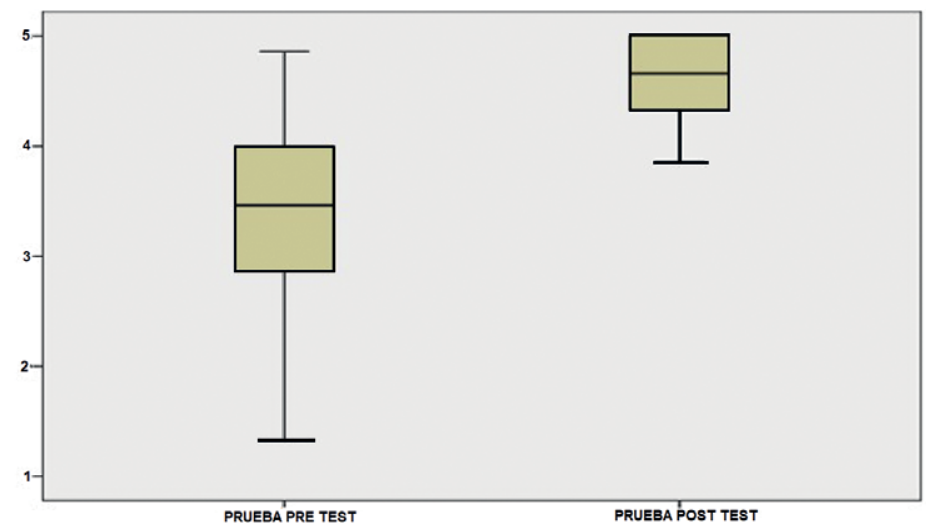

Gráfica 3. Comparación pre-test post test, grupo de Enfermería. 


\section{DISCUSIÓN}

El impacto de las tecnologías de la información y comunicación (TICs) es evidente en diversos campos; entre ellos: la educación. Éstas permiten dinamizar la enseñanza, el aprendizaje y los procesos de evaluación ${ }^{19}$.

El e-learning facilita los procesos porque ofrece métodos eficaces para la enseñanza-aprendizaje con diversidad de Recursos Educativos Digitales (RED), que responden a las características de las generaciones actuales, quienes están inmersas en nuevas tecnologías y en internet. Esto ha permitido la democratización del conocimiento y, cuando se utilizan estos recursos en educación, se permite a los estudiantes ir a su propio ritmo, repetir los contenidos las veces que requieran y conectarse desde cualquier dispositivo, en cualquier momento y lugar. Asimismo, como lo expresan Ferro et al, el proceso de enseñanza-aprendizaje mediado por las TICs da la posibilidad de adaptar las necesidades y características de los usuarios en su formación y preferencias ${ }^{20}$.

Para implementar los espacios virtuales surgen las plataformas de gestión de aprendizaje, las cuales son herramientas para la creación de entornos de enseñanza-aprendizaje; integran materiales didácticos y herramientas de comunicación, colaboración y gestión educativa ${ }^{21}$. La plataforma LMS Moodle es una de éstas y es a través de ella que la Universidad Nacional de Colombia pone a disposición cursos virtuales constituidos por RED diversos, como en este caso el de SVB.

La virtualización de cursos y contenidos temáticos en el campo educativo ha tenido un crecimiento trascendental en el mundo. La Universidad Nacional de Colombia no ha sido ajena a este desarrollo. Se ha destacado por la oferta de un significativo número de experiencias innovadoras construidas por equipos interdisciplinarios de docentes, pedagogos, ingenieros, diseñadores y comunicadores, a través del apoyo que ofrece la Dirección de Innovación Académica (DNIA), dependencia que tiene como misión analizar, diseñar, implementar y evaluar estrategias y herramientas tecnológicas que fomentan el uso y la apropiación de los medios y tecnologías de información y comunicación (MTIC). Formula propuestas y coordina mecanismos de fortalecimiento en los procesos de enseñanza-aprendizaje en los diferentes niveles y programas académicos de la Universidad. Además, promueve procesos de investigación que favorecen el uso y desarrollo de recursos tecnológicos como medio para generar innovación educativa ${ }^{22}$. Mediante convocatorias esta dependencia ofrece a los docentes de la universidad la posibilidad de construir o adecuar RED como estrategia para estimular el aprendizaje de los estudiantes en los diferentes programas curriculares de pregrado y posgrado.

El curso SVB, objeto del presente estudio, tiene una modalidad mixta para que el estudiante en un primer momento, a través del recurso educativo digital, adquiera los conceptos y observe los procedimientos y técnicas a utilizar según el caso de la situación de emergencia que se desarrolla (paro cardiaco, obstrucción de la vía aérea por cuerpo extraño, accidente cerebrovascular y síndrome coronario agudo). De esta forma, se pretende que una vez en el plano práctico (sesión presencial) pueda desarrollar las habilidades requeridas para una adecuada atención mediante la simulación clínica; sin embargo, este último no es objeto de evaluación en el presente estudio.

El uso de RED en este estudio es consecuente con los beneficios hallados por Parra et al. en estudiantes de Terapia Ocupacional, quienes concluyen que la implementación de los Objetos Virtuales de Aprendizaje favorece en los estudiantes la motivación, el aprendizaje autorregulado y la apropiación de conceptos, así como conocimientos relacionados con la asignatura; por tanto, lo proponen como estrategia de aprendizaje ${ }^{12}$. 
El uso de herramientas virtuales para la enseñanza y el aprendizaje de maniobras y técnicas de cuidado es una posibilidad válida al permitirle al estudiante la visualización de las mismas, la explicación y la repetición las veces que considere. Hoy se introduce el concepto de laboratorios virtuales, los cuales están disponibles en la web y son capaces de simular las condiciones de un determinado laboratorio, con múltiples ventajas como las describe Infante y dentro de las que se incluyen la variedad metodológica, flexibilidad, fácil acceso, atractiva presentación de contenidos, posibilidad de contar con nuevos entornos y situaciones problema, así como la optimización de recursos y costos ${ }^{23}$. Es decir, en otras áreas del conocimiento, al igual que en la enseñanza de la reanimación cardiopulmonar, se combinan actividades presenciales y virtuales conocidas como blended learning (b-learning), al facilitar el desarrollo de competencias que en última instancia se espera que se reflejen en el actuar.

La AHA, a través de las Guías para Reanimación Cardiopulmonar y Atención Cardiovascular de Emergencia (ACE) 2015, hace énfasis en la importancia de la educación para que los conocimientos científicos se trasladen a la práctica y las victimas puedan recibir una atención de calidad. Considera una alternativa muy razonable el autoaprendizaje mediado por videos y módulos combinados con la práctica ${ }^{6}$.

J.B. López Messa et al., citado por Parrilla Ruiz et al, refieren que la nueva metodología formativa en RCP, en la que se utiliza una fase no presencial previa con metodología e-learning, disminuye el tiempo de la fase presencial con una adquisición de conocimientos y habilidades similares al curso clásico recomendado por el ERC24.

Los resultados del presente estudio, en relación con el nivel de conocimientos medido a través del pre test antes de la exposición del grupo al recurso educativo digital, es bajo, con medias de 2.7, 2.49 y 3.38 en cada uno de los grupos respectivamente; similar a los hallazgos de Fernández E. y García R., quienes compararon tres métodos de enseñanza de reanimación básica en enfermeras que incluía una sesión teórica apoyada con diapositivas en power point seguida de demostración y práctica con un simulador en dos grupos y un tercer grupo con una sesión teórica mediante video con medias de $6.67,6.53$ y 6.67 respectivamente en cada grupo. Estos valores mejoraron notablemente en todos los grupos de ambos estudios con un incremento significativo en los conocimientos ( $\mathrm{P}<0.05)$, y fue similar en todos los grupos de uno y otro estudio 25.

En el trabajo de Tobase L et al., realizado en la Universidad de Sao Paulo, cuyo objetivo era desarrollar y evaluar un curso de SVB en línea, en el que igualmente utilizaron dos evaluaciones antes y después en un curso alojado en la plataforma Moodle para evaluar el conocimiento teórico, los resultados fueron similares con un incremento significativo en el aprendizaje con valores en la prueba $\mathrm{T}$ pareada de $6.4^{+/}-1.61$ y $9.3^{+/-0.82} \mathrm{p}<0.001^{26}$.

Una limitación del presente estudio fue haber dejado el curso sin restricciones al inicio, lo que permitió al estudiante avanzar revisando los diferentes módulos acordes con sus preferencias. Esto obvió en unos pocos participantes la realización del pre-test, por lo cual se tuvieron que excluir de la investigación.

\section{CONCLUSIÓN}

El recurso educativo digital, que forma parte del curso Soporte Vital Básico de la Facultad de Enfermería de la Universidad Nacional de Colombia, logró que los grupos se compactaran, alcanzaran en su mayoría notas superiores y disminuyera la dispersión. En este sentido, favoreció el 
aprendizaje e incrementó el conocimiento, requisito necesario en la formación como primer respondiente ante situaciones de emergencia como el PCR, OVACE, ACV y SCA.

Los resultados fueron similares en tres grupos de estudiantes de pregrado de programas diferentes. Esto permite inferir que no influye el área o nivel de formación del participante, dada la naturaleza de contenidos y diseño del recurso educativo digital, lo cual ofrece la oportunidad de ser cursado por cualquier persona de la comunidad.

Se requieren otras investigaciones para identificar la estabilidad del nivel de conocimientos a lo largo del tiempo, así como el momento adecuado para el reciclaje en los integrantes de la comunidad universitaria beneficiarios del proyecto UN SALVAVIDAS, en el que podría emplearse nuevamente el recurso educativo digital mencionado. La percepción de los participantes frente al recurso educativo digital es objeto de otro estudio.

\section{RESPONSABILIDADES ÉTICAS}

Protección de personas y animales. Los autores declaran que en esta investigación no se realizaron experimentos en personas o animales. Se adoptaron los lineamientos de Resolución 8430 de 1993 y se considera como una investigación de bajo riesgo, dado que emplea el registro de datos a través de procedimientos comunes.

Confidencialidad. Los autores declaran que se protegió la confidencialidad de los participantes. Apoyo financiero y patrocinio. Ninguno.

Conflicto de intereses. Los autores declaran ausencia de conflicto de intereses en el desarrollo de la presente investigación.

Reconocimientos. Los autores agradecen a los estudiantes que participaron en el proyecto de extensión solidaria UN SALVAVIDAS por su disposición y colaboración.

\section{REFERENCIAS}

1. Moreno PR, Del Portillo JH. Isquemia miocárdica: conceptos básicos, diagnóstico e implicaciones clínicas. Primera parte. Rev Colomb Cardiol. 2016; 23(5): 403-9. http://dx.doi.org/10.1016/j.rccar.2016.06.009

2. Borja I, James S, Agewall S, Antunes MJ, Bucciarelli-Ducci Ch, Bueno H, et al. Guía ESC 2017 sobre el tratamiento del infarto agudo de miocardio en pacientes con elevación del segmento ST. Rev Esp Cardiol. 2017; 70(12): 1082.e1-e61. https://doi.org/10.1016/j.recesp.2017.10.048

3. Ministerio de Salud y Protección Social de Colombia. Guía de práctica clínica para el síndrome coronario Agudo. Colombia: Minsalud; 2013. https://bit.ly/39C8V2P

4. Leal-Forero LC, Martínez-Malo LC, Navarro-Vargas JR. La reanimación cerebro cardiopulmonar estado del arte. Rev. Fac. Med. 2014; 62(1):149-55. http://dx.doi.org/10.15446/revfacmed.v62n1.43784

5. Morais DA, Carvalho DV, Correa A. Out-of-hospital cardiac arrest: determinant factors for immediate survival after cardiopulmonary resuscitation. Rev. Latino-Am. Enfermagem. 2014; 22(4): 562-8. http://dx.doi.org/10.159o/0104-1169.3453.2452

6. American Heart Association. Aspectos destacados de la actualización de las guías de AHA para RCP y ACE de 2015. Dallas, Texas: AHA; 2015. https://bit.ly/2UXfPvs

7. Asencio-Gutiérrez JM, Reguera-Burgos I. La opinión de los profesionales sanitarios sobre la presencia de familiares durante las maniobras de resucitación cardiopulmonar. Enferm Intensiva. 2017; 28(4): 144-59. http://dx.doi.org/10.1016/j.enfi.2017.01.002 
8. Cantú-Ríos R, Fernández M, Mercado-Longoria R, Pizaña-Serna A, Zamora-Menchaca JA, GonzálezReyna $R$, et al. Sobrevida y calidad de vida en pacientes con paro cardiorrespiratorio extrahospitalario en la ciudad de Monterrey, Nuevo León, México. Med Univer. 2012; 14(56): 145-9.

9. Machado F, Cabrera M, Morillo S, Rivedieu F, García F, Sgorlo F. Paro cardíaco extrahospitalario. Presentación y supervivencia al ingreso hospitalario en algunos centros urbanos y suburbanos del departamento de Maldonado, Uruguay. Análisis de 12 años. Rev.Urug.Cardiol. 2018; 33(2): 20-34. http://dx.doi.org/10.29277/cardio.33.2.2

10. Navarro-Patón R, Freire-Tellado M, Basanta-Camiño S. Barcala-Furelos R, Arufe-Giraldez V, RodriguezFernández JE. Effect of 3 basic life support training programs in future primary school teachers. A quasiexperimental design. Med Intensiva. 2018; 42(4): 207-15. https://doi.org/10.1016/j.medin.2017.06.005

11. Ortegón-Cetina CJ, Santos-Rodríguez MN, Sierra-Basto G. Calidad de reanimación cardiopulmonar avanzada efectuada por residentes de primer año en un hospital de segundo nivel. Inv Ed Medicina. 2017; 6(21): 47-51. https://doi.org/10.1016/j.riem.2016.05.009

12. Parra-Esquivel EI, Peñas-Felizzola OL, Gómez- Galindo AM. Objetos virtuales para el aprendizaje autorregulado de estudiantes de terapia ocupacional. Rev. Salud Pública. 2017; 19(6): 760-5. https://doi.org/10.15446/rsap.v19n6.62966

13. Hernández-Sampieri R, Fernández-Collado C, Baptista-Lucio P. Metodología de la Investigación. $6^{a}$ ed. México: Mc Graw Hill. 2014. https://bit.ly/39CEdGL

14. Zamora-Graniel FG, De los Santos-Rodríguez M, Sierra-Basto G, Luna-Rodríguez E. Calidad en habilidades de resucitación cardiopulmonar básica asociada a la fidelidad de simulación en pregrado. Inv Ed Med. 2015; 4(13): 22-7.

15. Rey-Graña C, Ramil-Díaz M. Introducción a la estadística descriptiva. $2^{\mathrm{a}}$ ed. España: Netbiblo; 2007. https://bit.ly/2SuaSZy

16. Crespo-Abril F. Métodos estadísticos: Ejercicios Resueltos y teoría. España: Editorial Universidad Politécnica de Valencia; 2017.

17. Ministerio de Salud y la Protección Social de Colombia. Resolución 8430 de 1993 Por la cual se establecen normas académicas, técnicas y administrativas para la investigación en salud. Colombia: Minsalud; 1993. https://bit.ly/2Swd2ry

18. Consejo superior Universitario de la Universidad Nacional de Colombia. Acuerdo o35 de 2003: Por el cual se expide el reglamento sobre propiedad intelectual en la Universidad Nacional de Colombia. Colombia: Universidad Nacional de Colombia; 2003. https://bit.ly/31WiR4y

19. Rodríguez-Espinoza A. La Universidad Estatal a Distancia de Costa Rica (UNED) y la virtualización de su oferta académica. Un análisis reflexivo de su puesta en práctica. Educare. 2017; 21(3): 1-28. http://dx.doi.org/10.15359/ree.21-3.23

20. Ferro-Soto C, Martínez-Senra AI, Otero-Neira MC. Ventajas del uso de las TICs en el proceso de enseñanza-aprendizaje desde la óptica de los docentes universitarios españoles. Edutec. 2009; 29: 1-12. https://doi.org/10.21556/edutec.2009.29.451

21. Rojas-Machado N, Pérez-Clemente F, Torres-Milord I, Peláez-Gómez E. Las aulas virtuales: una opción para el desarrollo de la Educación Médica. Rev EDUMECENTRO. 2014; 6(2): 231-47. https://bit.ly/2SNqO7Z

22. Universidad Nacional de Colombia. Dirección Nacional de Innovación Académica Colombia. Colombia: UNAL; 2019. http://www.dnia.unal.edu.co

23. Infante-Jiménez C. Propuesta pedagógica para el uso de laboratorios virtuales como actividad complementaria en las asignaturas teórico-prácticas. RMIE. 2014; 19(62): 917-37. https://bit.ly/2Hr5EaL 
24. Parrilla-Ruiz FM, Cárdenas-Cruz D, Cárdenas-Cruz A. Futuro de la metodología formativa en reanimación cardiopulmonar básica para población general. Atención Primaria. 2013; 45(3): 127-78. http://dx.doi.org/10.1016/j.aprim.2012.10.011

25. Fernández-Rangel E, García-Rodríguez RM. Comparación entre tres métodos de enseñanza de reanimación cardiopulmonar básica en enfermeras del hospital San José Tec de Monterrey. Rev avances. 2007; 4(11): 36-44. https://bit.ly/2UU2eoP

26. Tobase L, Peres HHC, Almeida DM, Tomazini EAS, Ramos MB, Polastri TF. Instructional design in the development of an online course on Basic Life Support. Rev Esc Enferm USP. 2017; 51: e03288. http://dx.doi.org/10.159o/S1980-220X2016043303288 